\title{
Epidemiologia e desigualdade: notas sobre a teoria e a história
}

\author{
Jarbas Barbosa da Silva e Marilisa Berti Azevedo Barros²
}

RESUMO O presente artigo analisa historicamente o conceito de desigualdade e aborda o tratamento dado à
desigualdade em saúde. São analisadas as desigualdades naturais e sociais, o conceito de equiidade, as
explicações teóricas sobre a desigualdade e a estratificação nas sociedades modernas. Finalmente, são
analisadas as relaçóes entre os estudos sobre desigualdades sociais em saúde
e a epidemiologia, desde o nascimento dessa disciplina, passando pela era bacteriológica e chegando aos
dias de hoje, em que cresce o interesse pelo tema.

Palavras-chave Epidemiologia, história, classe social, distribuição de bens e serviços, eqüidade.

As desigualdades entre os humanos constituíram-se em objeto de reflexão desde que, na Grécia dos séculos VI e VII a.C., operou-se a transição do mito para o pensamento racional, inaugurando a filosofia (1). O nascimento da polis e da democracia ateniense propiciaram reflexões sobre a política, inclusive sobre a distribuição de bens, direitos e obrigações entre os cidadãos e entre esses e os escravos. Aristóteles, um dos primeiros a refletir sobre as desigualdades, apresentou princípios de igualitarismo que, legitimando as práticas sociais vigentes, justificavam, como naturalmente determinados, os desníveis existentes entre os seres humanos, já que alguns estariam destinados a comandar e outros, a obedecer (2).

Desde então, diversos pensadores analisaram a sociedade tomando a questão das desigualdades como objeto, justificando-as como derivadas dos desígnios divinos ou decorrentes de uma natureza humana abstrata, ou contestando-as como injustas e derivadas da maneira como os seres humanos constroem sua história. As noções de igualdade e desigualdade

\footnotetext{
Ministério da Saúde, Fundação Nacional de Saúde, Centro Nacional de Epidemiologia. Correspondência e pedidos de separatas devem ser enviados a este autor no seguinte endereço: Centro Nacional de Epidemiologia/CENEPI/FUNASA, SAS, Quadra 4, Bloco N, Sala 600, CEP 70058-902, Brasília (DF) Brasil.E-mail: jarbas.barbosa@ funasa.gov.br

2 Universidade de Campinas, Departamento de Medicina Social, Campinas (SP), Brasil.
}

remetem a dimensões específicas de análise, na medida em que todos podem ser considerados iguais aos outros se tomados por uma característica genérica o suficiente para ser extensiva a qualquer um; ou podem ser considerados completamente desiguais, se comparados por condição tão restritiva que resulte em uma quase individualização. A qualidade de ser igual ou desigual possui caráter apenas descritivo, sem associação necessária com um juízo de valor sobre justiça ou injustiça.

O objetivo do presente trabalho foi realizar uma revisão histórica do conceito de desigualdade e abordar o tratamento que lhe tem sido conferido, no campo da saúde, desde o advento da epidemiologia.

\section{DESIGUALDADES NATURAIS E SOCIAIS}

As desigualdades geralmente são classificadas como naturais quando ocorrem como diferenças ou dessemelhanças entre os indivíduos, como no caso de sexo, raça e idade; ou como sociais, quando sua ocorrência é associada com a estrutura da sociedade onde estão inseridas. As desigualdades sociais se originam na ocupação de posições diferentes no que diz respeito à organização social do processo de produção e, conseqüentemente, ao acesso a bens cuja disponibilidade é escassa (3). As desigualdades sociais têm sido descritas como ocorrendo em todas as sociedades conhecidas ${ }^{3}$, embora com padrões e causalidades variáveis.

As desigualdades naturais não determinam a ocorrência das desigualdades sociais e são, muitas vezes, condicionadas por estas. Diferenças naturais como as de sexo, raça, força, estatura, inteligência e fecundidade só propiciam o surgimento de desigualdades sociais quando são utilizadas por uma sociedade como critério para a atribuição de papéis sociais (4). Mesmo assim, a desigualdade, mesmo aquela socialmente determinada, não remete, necessariamente, à idéia de injustiça. Esta exige um julgamento de valor, encontrando-se melhor consubstanciada na noção de iniqüidade. $\mathrm{O}$ conceito de iniqüidade, diferentemente dos conceitos de diferença e desigualdade, não se reveste de caráter apenas descritivo, mas sim normativo, na medida em que sempre pretende enunciar um "deveser".

\section{O CONCEITO DE EQÜIDADE E AS DESIGUALDADES EM SAÚDE}

Utilizado no âmbito do direito para representar a ascendência da justiça sobre a legalidade, o conceito de eqüidade, ou a sua falta, a iniqüidade, tem sido empregado em análises sobre desigualdades sociais em saúde para qualificar aquelas consideradas como inaceitáveis, por sua elevada 
magnitude ou por sua já demonstrada vulnerabilidade a ações factíveis. Esse julgamento, contudo, especialmente ao tratar de questões como níveis de saúde, necessariamente exige o estabelecimento, a priori, de uma linha divisória, que será tomada como parâmetro de justo ou injusto, orientada, em grande parte, por princípios morais, éticos e políticos, que são historicamente dados.

Assim, sempre há provisoriedade na utilização dos qualificativos "boa" ou "má" para descrever a condição de saúde, na medida em que tais qualificativos estão necessariamente circunscritos ao momento em que são aferidos. Pode-se então, falar de iniqüidades em saúde não enquanto um valor abstrato, mas sim como uma manifestação mensurável da injustiça social, geralmente representada pelos diferenciais no risco de adoecer ou morrer. Esses riscos, por sua vez, se originam das condições heterogêneas de existência e de acesso a bens e serviços, inclusive os de saúde. Os melhores níveis de saúde efetivamente alcançados por certos grupos sociais, em dado momento, passam a ser um limite que poderia ser universalizado caso a sociedade fosse mais igualitária quanto às características que determinam esses diferenciais, embora ainda se distanciem do parâmetro estabelecido pelo "deve-ser". A desigualdade pode ser fator tanto de produção quanto de superação de iniqüidades, como ressaltado por Kadt e Tasca (5), visto que uma discriminação positiva operaria no sentido de dar tratamento desigual para reduzir as distâncias sociais.

Há vertentes na sociologia, entre os funcionalistas, e na política, entre os liberais, que consideram a estratificação decorrente das desigualdades sociais como insuperável (o que seria comprovado pelo fato de sempre ter ocorrido, ainda que sob as mais variadas maneiras de

\footnotetext{
É controversa a existência de sociedades humanas primitivas sem qualquer traço de desigualdade, completamente igualitárias.
}

organização social) e desejável, por ser capaz de desempenhar um papel motivador sobre as camadas "de baixo" existentes nas sociedades. Outras vertentes entendem as desigualdades como injustas e mutáveis $(6,7)$.

\section{EXPLICAÇÕES PARA \\ A DESIGUALDADE: \\ A ESTRATIFICAÇÃO NAS SOCIEDADES MODERNAS}

O iluminista Jean-Jacques Rousseau, pioneiramente, em 1755, distinguiu dois tipos de desigualdade (8): a natural ou física, "estabelecida pela natureza e que consiste na diferença das idades, da saúde, das forças do corpo e das qualidades do espírito e da alma", e a moral ou política, que "depende de uma espécie de convenção e que é estabelecida ou, pelo menos, autorizada, pelo consentimento dos homens", apresentando uma causalidade social e expressando-senos "vários privilégios de que gozam alguns em prejuízo de outros" (p. 235).

Dentre os vários sistemas explicativos para o fenômeno da estratificação social nas sociedades modernas, podem ser classificadas como matrizes teóricas a teoria marxista, que associou a existência das classes sociais à organização das relações de produção; a teoria funcionalista, que pensa a estratificação como conseqüência imediata da divisão do trabalho; e uma terceira teoria, esboçada inicialmente por Adam Smith, que relaciona a estratificação ao mercado (6).

Para o marxismo, a desigualdade na sociedade capitalista é resultado da divisão da sociedade em classes, sendo estas definidas, predominantemente, pelo tipo de relação de seus integrantes com os meios de produção. Esse critério diferencia radicalmente o conceito de classe utilizado pelo marxismo do conceito utilizado por outros sistemas teóricos, que tomam como base, geralmente, o nível de rendimento ou a propriedade. A proposta marxista assume uma concepção essencialmente dualística, enfatizando o papel da luta entre as classes fundamentais e antagônicas, que poderia ser considerada como o propulsor da história de todas as sociedades humanas existentes até então (9).

$\mathrm{Na}$ sociedade atual, entretanto, a previsão de uma progressiva simplificação das classes não se realizou, e agrupar todos os que não possuem meios de produção numa única classe social, o proletariado, significaria supor semelhanças de consciência, de condição social, ou mesmo de destino histórico entre indivíduos bastante diferenciados. Essa constatação, bem como a necessidade de caracterizar as classes médias, que não apenas sobreviveram como também se expandiram, tem levado marxistas contemporâneos a reinterpretar o conceito de classe, propondo novas conceituações, com menos ênfase em aspectos exclusivamente objetivos ou econômicos. Tal reflexão gerou uma reavaliação da configuração e da dinâmica das classes sociais e frações nas sociedades contemporâneas, reforçando a distinção em termos da identidade de valores e da representação política $(10,11)$.

Max Weber propôs uma análise da estrutura das desigualdades sociais baseada em três dimensões, ao mesmo tempo interdependentes e relativamente autônomas entre si: a da riqueza, a do prestígio e a do poder. Para Weber, classe pode ser definida como um grupo de pessoas que se encontra em igual situação quanto a um "conjunto de probabilidades típicas" (12):

a) de provisão de bens; b) de posição externa; c) de destino pessoal, que derivam, dentro de uma determinada ordem econômica, da magnitude e natureza do poder de disposição (ou da carência dele) sobre bens e serviços e das maneiras de sua aplicabilidade para a obtenção de rendimentos (p. 242). 
A difícil operacionalização desse complexo sistema tem limitado os estudos que se inserem nessa tradição teórica a utilizarem quase exclusivamente indicadores de status, como renda ou grau de instrução, para estabelecer a noção de estratificação social.

Por outro lado, os estratos sociais podem ser tomados como agrupamentos de indivíduos, definidos a partir de indicadores mensuráveis, podendo constituir-se em simples agregados estatísticos, com utilização relativamente restrita aos aspectos descritivos, distinguindo-se do conceito de classe social proposto por Marx. Na análise de estratos sociais, a visão das classes como agentes históricos é substituída por análises estatísticas de distribuição da renda, instrução e prestígio; a análise da diferenciação social é separada da análise do conflito (10).

A diversidade de sistemas teóricos que procuram analisar os mecanismos de criação das desigualdades sociais e a própria dificuldade em traduzir os conceitos de tais sistemas em estudos empíricos levam vários investigadores do processo saúde-doença a utilizar aproximações para apreender problemas de causalidade das desigualdades. Várias aproximações têm sido utilizadas, levando em conta a associação entre diversos recortes sociais (como gênero, grupos étnicos e religiosos) e caracterizações territoriais com as condições de vida (entendidas como o conjunto das condições materiais necessárias à subsistência e que são fortemente condicionadas, ainda que com mediações, pelos modelos vigentes de organização da produção social). Essas variáveis teriam um poder explicativo relevante, inclusive porque sua abordagem integra fenômenos socioeconômicos coletivos.

\section{EPIDEMIOLOGIA E DESIGUALDADE: UMA SAGA INCONCLUSA}

Uma das mais utilizadas definições da epidemiologia - estudo da distribuição e dos determinantes da freqüência das doenças em seres humanos (13) - contém a premissa de que o evento doença apresenta uma determinada distribuição, ou seja, uma repartição desigual ou variável entre a população. Assim, caberia à epidemiologia tanto a descrição desses diferenciais de acometimento quanto a busca de explicações etiológicas para essas desigualdades. Caso as doenças e demais eventos relativos à saúde se distribuíssem de maneira absolutamente aleatória e, portanto, não determinista, não existiria a epidemiologia ou, pelo menos, não como é conhecida hoje.

$\mathrm{O}$ olhar sobre as desigualdades no acometimento da doença, bem como as tentativas de explicá-las, estão presentes em Hipócrates, que buscou estabelecer relações entre as condições ambientais e a propensão a apresentar certos quadros de doenças (14). Também estão presentes em Snow, que procurou explicar os diferenciais encontrados na epidemia de cólera que assolou Londres no século XIX (15). A natureza dessas desigualdades, que a epidemiologia tentou medir e explicar, assim como o cenário onde estavam inseridas, é que variou bastante, acompanhando as transformações ocorridas nos processos políticos e sociais.

Mesmo em uma época em que o termo epidemiologia se referia, provavelmente, apenas à descrição das epidemias que então se instalavam na Europa, Georg Agricola publicou, em 1556, uma análise em que utiliza o elevado número de viúvas e as altas taxas de repetição de casamentos entre estas para demonstrar que havia uma mortalidade mais alta e mais precoce entre os homens que trabalhavam nas minas subterrâneas dos montes Cárpatos (16). Embora haja registros de que já no século XVIII a associação entre pobreza e mortalidade havia sido sugerida (17), foi somente na primeira metade do século XIX que se desenvolveram, de maneira sistetemática, as investigações sobre as relações entre o processo saúdedoença e as profundas desigualdades sociais da época.

Foi grande o impacto da revolução industrial sobre as condições de vida dos habitantes das cidades européias. Agravou-se um quadro sanitário já bastante precário: estimativas da esperança de vida ao nascer para as diferentes paróquias de Londres entre 1570 a 1653 revelaram médias de 25,0 a 43,5 anos, para os piores e melhores estratos sociais, respectivamente. Além disso, uma análise da mortalidade em Genebra no século XVII estimou a esperança de vida ao nascer em apenas 18,5 anos para a classe baixa, em 24,7 anos para a média e em 35,9 anos para os longevos da época, situados na classe mais alta (18).

As profundas modificações sociais, econômicas e políticas desse período impulsionaram estudos epidemiológicos sobre as precárias condições de vida experimentadas nas cidades (19). Essa incipiente produção contemplou esse objeto com olhares diferenciados e, em alguns casos, abertamente antagônicos. Por um lado, os partidários da medicina social, em grande parte vinculados aos movimentos políticos de contestação e aos vários socialismos existentes na época (20), denunciaram e tentaram explicar as causas das dramáticas condições de vida das classes trabalhadoras, que, paradoxalmente, com o advento da nova sociedade, viam, inclusive, agravar-se.

A efervescência política e social, cujo ápice foi o movimento revolucionário que percorreu a Europa, a partir de Paris, entre 1848 e 1850, influenciava fortemente os integrantes dos movimentos da saúde pública (21). Vários dos socialistas dessa primeira metade do século XIX, principalmente Charles Fourier e Saint-Simon, na França, e Robert Owen na Inglaterra, bem como seus seguidores, ao analisar os problemas sociais da época e construir seus projetos utópicos de sociedades, 
escreveram sobre aspectos dos problemas de saúde pública $(20,21)$.

Representante dessa vertente, apontado inclusive como fundador da epidemiologia social (22), o jovem Engels registrou as terríveis condições de vida nos bairros operários de Manchester em A situação da classe trabalhadora na Inglaterra (23, 24). Engels enfatizou os diferenciais do risco de morte prematura associados com a condição social, como, por exemplo, a duração média da vida em Liverpool, onde a expectativa de vida entre as classes mais elevadas situavase em 35 anos, reduzindo-se para 22 anos entre negociantes e chegando a apenas 15 anos para os operários (24).

Por outro lado, também se observa, nessa época, o exame das desigualdades sociais para subsidiar plataformas reformadoras que diminuíssem as tensões continuamente produzidas pelo ambiente generalizado de exploração brutal sobre as classes trabalhadoras. Autores como Luís Villermé e William Farr podem ser considerados como precursores das contemporâneas aplicações da epidemiologia na detecção de grupos populacionais sob maior risco de adoecimento e morte, com o objetivo de orientar a tomada de decisões na planificação de políticas de saúde. São originários do desenvolvimento da aritmética política, que havia sido fundada na metade do século XVII por William Petty e aperfeiçoada por John Graunt, que aplicou essas noções na área da saúde. A obra de Villermé teve grande impacto na regulamentação do trabalho infantil na França, em 1841, enquanto Farr, na direção do Escritório do Registro Geral britânico, produziu as estatísticas que serviram de subsídio a ações reformadoras como as de Chadwick (25), que propôs medidas e leis que organizaram a interferência do Estado britânico nas questões sanitárias mais importantes da época (21).

A contribuição de Villermé é indiscutivelmente original no estudo de diferenciais intra-urbanos de saúde, com base territorializada. Já em 1826, analisou a mortalidade em diferentes setores da cidade de Paris $(19,21)$; em 1840, em seu trabalho sobre operários das indústrias de algodão (26), lã e seda, observou que "para encontrar 100 homens aptos para o serviço militar, faz-se necessário recrutar 193 da classe endinheirada, e até 343 da classe pobre" (p. 37).

Do outro lado do Canal da Mancha, William Farr implantou, em 1839, o primeiro registro de morbimortalidade, na Inglaterra. A partir da década de 1860, Farr produziu diversos estudos destinados a explicar os diferenciais de mortalidade observados quando se analisavam os óbitos ocorridos nas classes que ele construíra baseando-se nos grupos profissionais presentes nas sociedades industriais da época (27).

Com esse referencial, Farr analisou os diferenciais de mortalidade entre mineiros e não mineiros de vários distritos da Grã-Bretanha, concluindo que até a idade de 35 anos não havia diferenças significativas entre os dois grupos; porém, nos grupos etários posteriores, a mortalidade era marcadamente maior entre mineiros (28). Essa primeira tentativa de estratificação social, para análise de eventos como doenças e mortes, só foi retomada nos anos 1920, na própria Inglaterra (27).

Ainda na primeira metade do século XIX, merecem registro os estudos de Quételet, na Bélgica, e Stanway, na Inglaterra, que compararam alguns aspectos do desenvolvimento do peso e altura, o primeiro entre grupos "favorecidos" e "miseráveis" e o segundo entre trabalhadores de fábrica e indivíduos que não precisavam trabalhar para garantir o sustento (17). Nessa mesma época, Snow procurou apontar diferenciais de acometimento ligados à condição social nas epidemias de cólera. Esse autor chamou a atenção para o aumento na incidência de cólera entre a classe trabalhadora, relacionando-o com a exigüidade das casas nos bairros proletários, que obrigava os indivíduos a fazer refeições no mesmo ambiente em que se encontravam as pessoas doentes (15).
Também os operários, no caso, os mineiros, mereceram uma detalhada explicação de suas condições de vida e trabalho, para justificar a maior incidência de cólera entre estes, se comparada à incidência entre indivíduos com outros ofícios.

\section{A SUBMERSÃO DA DIMENSÃO SOCIAL}

A partir dos estudos de Snow sobre a cólera, que forneceram as provas epidemiológicas, e das descobertas de Pasteur e Koch, que forneceram as provas microbiológicas, as teorias contagionistas, que vinham experimentando franco declínio, ressurgiram e se firmaram nas três últimas décadas do século XIX como explicação hegemônica para a causalidade das doenças. Assim foi inaugurado um longo período, conhecido como era bacteriológica (21).

As sucessivas e rápidas descobertas dos agentes etiológicos das principais doenças prevalentes na época criaram as condições para o fortalecimento de um modelo explicativo do processo saúde-doença, que o reduziu a uma relação quase exclusivamente biológica e monocausal entre os humanos, de um lado, e as bactérias, os vírus e os protozoários do outro. $\mathrm{O}$ advento da era bacteriológica representou uma derrota para todas as concepções identificadas com os fantasmagóricos miasmas e ofuscou linhagem dos estudos que procuravam relacionar doença com situação social. A atenção do campo da saúde voltou-se, então, quase que exclusivamente para as alentadoras promessas contidas na perspectiva de descoberta dos agentes etiológicos das doenças, e para as possibilidades de desenvolvimento de instrumentos de prevenção e controle. Um clima de otimismo acompanhou o pensamento de um século que chegava ao fim embalado por grandes sínteses em praticamente todos os campos científicos, fornecendo a ilusão de que a ciência estaria, no essencial, definitivamente concluída (29). Essa 
ilusão, como se sabe hoje, não se sustentou por muito tempo.

O hemisfério norte viveu, a partir do último quarto do século XIX, um período de expansão econômica que durou até a metade da segunda década do século XX. Essa expansão propiciou reformas sociais que promoveram uma melhoria geral das condições de vida das classes trabalhadoras, com importantes repercussões para o aumento da expectativa de vida, o conseqüente envelhecimento das populações e as modificações no perfil de adoecimento e morte. Houve uma progressiva substituição das doenças infecciosas e parasitárias pelas doenças crônico-degenerativas. Assistiu-se, assim, à substituição da idade das pestilências e da fome pela idade do declínio das pandemias, para depois se chegar até a idade das doenças degenerativas e das doenças provocadas pelo ser humano. Esse processo foi denominado de transição epidemiológica em sua versão clássica ou ocidental (30), e desencadeou a necessidade de transformações importantes nos modelos de estudo da causalidade das doenças, que procuram dar conta da maior complexidade dos processos agora envolvidos.

No início da segunda década do século $X X$, quando Goldberger procurou estabelecer a etiologia da pelagra, podem ser reconhecidos novos indícios de investigação da dimensão social no processo saúdedoença (17), tendo sido analisadas suas relações com a pobreza urbana e rural, pelas diferenças de alimentação presentes entre esses dois "tipos" de pobres (31). Os estudos sobre mortalidade de Stevenson, criador do primeiro sistema de classificação social baseado em grupos ocupacionais, na Inglaterra, em 1911, foram publicados no início da década de 1920. Neles, foi demonstrado que as taxas de mortalidade eram maiores entre estratos mais pobres, tendência que se acentuava ainda mais para algumas causas específicas como a bronquite $(27,32)$.
Outra exceção importante para esse longo período de silêncio foram os trabalhos de Mayor Greenwood, um dos membros fundadores da Associação Médica Socialista, em 1930. Greenwood foi responsável por importantes contribuições ao desenvolvimento de técnicas estatísticas para estudos epidemiológicos que buscavam associação entre câncer e estratificação social. De fato, esse autor constatou uma mortalidade por câncer maior entre classes mais baixas (33).

Nas décadas imediatamente seguintes há escassos registros de estudos sobre o tema das desigualdades sociais em saúde. Nesse período, o desenvolvimento de técnicas para a realização de estudos etiológicos é acompanhado por um afastamento cada vez maior da utilização do instrumental epidemiológico na avaliação e análise de situações de saúde. Esse período de silêncio é quebrado, de maneira ocasional, como apontado por Illsey e Baker (34), por escassos estudos. Mais recentemente, nos anos 1960, merece registro a investigação de Antonovsky (35) sobre as relações entre classe social, mortalidade e expectativa de vida. Alguns estudos produzidos nesse período incorporaram os assim chamados fatores socioeconômicos apenas como mais uma das características individuais dos pesquisados (36), reduzindo o alcance da análise da dimensão social.

As pesquisas de investigação etiológica, que experimentam grande desenvolvimento no período posterior à II Guerra Mundial e incorporam importantes avanços metodológicos a partir dos anos 1960, necessitavam utilizar variáveis indicadoras de estratos socioeconômicos para permitir controlar seu possível papel de confundimento nas associações entre exposições e doenças (37). Um menor número dessas pesquisas etiológicas procurava verificar o papel das classes sociais como fator de risco para doenças crônico-degenerativas, utilizando diferentes sistemas de estratificação, principalmente a partir do tipo de ocupação, do nível de renda e do grau de instrução.

\section{PANORAMA ATUAL}

Na América Latina, a partir da metade dos anos 1970, iniciou-se, em alguns centros acadêmicos, primeiramente no México, Equador e Brasil, um movimento que procurava se diferenciar das posições então hegemônicas na saúde pública e na medicina preventiva. Essa vertente teórica buscou recuperar as idéias de causalidade social do processo saúde-doença que haviam entrado em declínio desde o advento da era bacteriológica, retomando, inclusive, em alguns países, a denominação originária de medicina social. No Brasil, esse movimento teve início em 1975 com a crítica de Arouca ao preventivismo e o estudo de Donnangelo sobre saúde e sociedade (38).

Assim como seus antecessores franceses, ingleses e alemães do século passado, os integrantes desse movimento também assumiram, via de regra, uma vinculação com o pensamento revolucionário de sua época, que pode ser identificada pela adesão explícita dos fundadores ao ideário marxista. Essa escola latinoamericana promoveu uma reinterpretação da epidemiologia sob o marco teórico do materialismo histórico, re-enquadrando o processo saúde-doença como fenômeno socialmente determinado.

Alguns autores se voltaram para a questão da desigualdade epidemiológica, evidenciada pela diferença entre as classes sociais em termos do risco de adoecimento e morte. Uma das contribuições da epidemiologia social ou crítica residiu na construção de abordagens para delinear perfis epidemiológicos de classe, como o proposto por Breilh (39). Esses estudos partiram do princípio de que o conceito marxista de classe social apresenta maior grau de concretude e significados do que os tradicionais estudos de estratificação. No início da década de 1980, intro- 
duzindo essa metodologia no Brasil, Barros (40) realizou um estudo sobre morbidade e consumo de medicamentos por classes sociais em Ribeirão Preto, Estado de São Paulo, utilizando um sistema que procurava caracterizar as classes fundamentais e as frações de classe existentes naquela sociedade.

A epidemiologia social, procurando utilizar o instrumental teórico e analítico marxista em contraposição ao funcionalista, chegou a se constituir, na América Latina, em importante alternativa à epidemiologia clássica ou tradicional. Contudo, perdeu substância, em anos posteriores, em parte devido à crise que então atravessavam o pensamento marxista e os movimentos de transformação das sociedades.

Na Europa, nos anos 1980, assistiuse a uma retomada do interesse pela análise das desigualdades sociais em saúde a partir do estudo que veio a ser conhecido pelo nome do coordenador do grupo que o produziu, Sir Douglas Black. O trabalho, que alcançou grande notoriedade pela polêmica que suscitou, foi publicado no momento em que os conservadores ascendiam ao poder, iniciando a era Thatcher. Sofreu, por seus resultados e propostas, uma frustrada tentativa de ocultá-lo da imprensa e da opinião pública, para em seguida ser frontalmente desautorizado pelo novo governo britânico (41).

Em 1984, sob o patrocínio da Organização Mundial da Saúde (OMS) foi realizado, na Dinamarca, um encontro sobre o tema "desigualdades em saúde na Europa". O encontro concluiu pela necessidade de melhores fontes de dados e de uma análise mais profunda e de melhor qualidade ambas consideradas insuficientes ou inexistentes na maioria dos países. Outro encontro, realizado em Portugal, em 1987, produziu resultados que serviram de base para o monitoramento do objetivo proposto pela OMS, de reduzir em $25 \%$ os desníveis entre países e entre grupos sociais de um mesmo país até o ano 2000 (42).
Nos anos 1990 ampliou-se a preocupação de pesquisadores e agências quanto à questão das iniqüidades em saúde. $\mathrm{Na}$ epidemiologia, avaliações oriundas de diferentes perspectivas teóricas trouxeram à tona questionamentos sobre ousadias condenáveis no uso do método epidemiológico, dadas as limitações inerentes aos estudos observacionais $(43,44)$; insuficiente formação médico-biológica dos epidemiologistas, conduzindo à produção de pesquisas com desenhos e análises ingênuas ou equivocadas (45); limitações metodológicas e paradigmas dominantes confrontados pelas novas frentes de avanço científico e pela iminência de uma nova era para a epidemiologia (46); e, a partir de uma perspectiva mais radical, críticas ao modelo hegemônico de causalidade (47), à insuficiência de conceitos e métodos de uma disciplina contida no figurino biomédico em constituir-se na disciplina básica da saúde pública $(48,49)$ e em dar conta do campo de uma epidemiologia social (50), eco-epidemiologia (47) ou macro-epidemiologia (48). O debate aflorou nos principais periódicos da área, explicitando posições divergentes (51-56). Os que acompanharam a produção da epidemiologia crítica latino-americana viram no debate internacional uma retomada de parte dos questionamentos contidos naquele movimento (57).

Os estudos sobre desigualdades sociais em saúde ganharam, na década de 1990, grande aporte, oriundo do desenvolvimento de métodos e desenhos de estudos; da diversificação dos eventos de saúde, que passaram a se constituir como objetos privilegiados de análise; da utilização de novas técnicas de mensuração de disparidades; e do acúmulo de conhecimentos sobre os principais vieses a que esses estudos estão sujeitos (58-61). No campo científico, ampliou-se o número de artigos sobre desigualdades sociais em saúde que se detinham não apenas em análises de taxas padronizadas de mortalidade, de esperança de vida e probabilidades de sobrevivência, mas que também aprofundaram as análises de mortes em subgrupos etários (62) ou por causas básicas específicas (63-65).

Outros eventos e indicadores de saúde incorporaram-se aos utilizados nas análises das iniqüidades: esperança de vida livre de incapacidades, mortes evitáveis (66), morbidades específicas (60, 63), incapacidades, deficiência física, acesso, uso e qualidade dos serviços de saúde, fatores de risco para doenças crônicas $(67,68)$ ou, ainda, autoavaliações de saúde (69). Diversificadas abordagens e desenhos passaram a ser utilizados e aperfeiçoados: estudos de agregados e de base individual, transversais ou de coorte, com ou sem vinculação com os bancos que geram numeradores e denominadores $(58,59)$.

Os estudos passaram a utilizar diferentes variáveis e classificações socioeconômicas na configuração dos estratos socioeconômicos ou das classes sociais $(58,59,70)$. Foram publicadas análises comparando o uso de diferentes classificações. Entre as variáveis, a ocupação ganhou espaço diferenciado, com status de variável socioeconômica fundamental, considerada como refletindo mudanças estruturais nas economias nacionais e internacional (71). Diferenciam-se, entre as classificações de ocupações, as hierárquicas das estruturais, estas com orientação marxista ou mais eclética (58). De outra perspectiva, pesquisadores propuseram mensurar as diferenças da distribuição do evento saúde entre os indivíduos, dispensando prévia definição do pertencimento a estratos socioeconômicos (72).

Diferentes indicadores compostos foram elaborados e propostos para estudos de base individual, servindo também, especialmente nas análises de agregados, como instrumento para a delimitação de áreas homogêneas $(58,60)$. A linhagem dos estudos de desigualdades sociais em saúde se viu assim beneficiada pelos avanços de vários campos: a concepção do estudo ecológico como modelo apropriado e válido, e não como substitutivo inferior dos estudos de base individual; o aprimoramento de 
técnicas para manipulação e vinculação de grandes bases de dados; o desenvolvimento das análises de séries temporais, das técnicas de georeferenciamento e das análises espaciais; e o desenvolvimento das análises de múltiplos níveis e de estratégias de análises de pequenas áreas.

Para quantificar e monitorar a disparidade social em saúde, inúmeras medidas foram propostas e ensaiadas, tendo Kunst (58) contabilizado 15 diferentes tipos de medidas que têm sido usadas por pesquisadores para sumarizar as diferenças observadas entre os estratos sob estudo. Esse autor analisa os limites, potenciais e aplicações de cada um desses tipos de medidas e propõe classificá-las com o uso das dicotomias: medidas absolutas ou relativas, de efeito ou de impacto, brutas ou modeladas. Kunst (58) reconhece que, embora extremamente úteis, tais medidas não podem substituir a descrição detalhada das taxas dos subgrupos estudados. A partir dos avanços dos estudos sobre desigualdades e iniqüidades em saúde, diferenciou-se uma linha de investigação que, buscando analisar o impacto do próprio grau de concentração de riquezas sobre a saúde, independentemente do nível de pobreza ou carência das populações estudadas, produziu achados consistentes e significativos, constatando piores riscos de morbimortalidade em áreas com maiores concentrações de renda (73-76).

Além dos avanços no campo técnicocientífico, houve um crescente envolvimento de agências governamentais e não governamentais, que passaram a promover oficinas, grupos de trabalho, forças-tarefa e a lançar iniciativas e programas voltados para o monitoramento e intervenções sobre as iniquiidades em saúde. Nos Estados Unidos, em 1994, realizou-se uma conferência cujo objeto foi a aferição de iniqüidades sociais em saúde (US Conference on Measuring Social Inequalities in Health), promovida pelos Institutos Nacionais de Saúde (NIH). Seu relatório final recomendou a inclusão e publicação de dados socioeconômicos nos bancos de estatísticas vitais, com destaque para a ocupação; no registro de doenças; nos inquéritos nacionais; e em pesquisas não governamentais financiadas com fundos federais (71). Em 1996, a OMS lançou um documento sobre eqüidade e saúde (77), tendo a Organização PanAmericana da Saúde (OPAS) se posicionado em 1995 sobre a questão (78). A Organização das Nações Unidas (ONU), com os relatórios sobre desenvolvimento humano, estimulou a discussão sobre indicadores e desigualdades sociais e o seu monitoramento; o Banco Mundial passou a priorizar as áreas de nutrição, saúde e população com a publicação, em 1997, de estratégia (Health, Nutrition and Population Sector Strategy, HNP) com vistas à redução da pobreza e de seu impacto na saúde. A Fundação Rockefeller lançou a iniciativa global de eqüidade em saúde (Global Health Equity Initiative), selecionando a questão da eqüidade em saúde como prioridade para atenção e suporte (79).

Também no continente latinoamericano houve uma revitalização da temática. A OPAS enfatizou a questão da superação das iniqüidades em saúde por intermédio de desenvolvimentos metodológicos para aperfeiçoamento das técnicas de aferição e dos modelos de análise, bem como pela defesa da inclusão desse tema entre as prioridades dos ministérios da saúde da região. A questão das iniqüidades em saúde passou a ter espaço qualificado nos principais congressos brasileiros de epidemiologia. Seminários e oficinas (80) aglutinam instâncias governamentais e acadêmicas em ini-

\section{REFERÊNCIAS}

1. Bernhardt J. O pensamento pré-socrático: de Tales aos sofistas. Em: Châtelet F, ed. História da filosofia. Vol. 1. Rio de Janeiro: Zahar; 1973. Pp. 23-64.
2. Machado LG. Política. Em: Rousseau JJ. Do contrato social. 3rd ed. São Paulo: Abril Cultural; 1983. (Série Os Pensadores). ciativas de definição de estratégias de intervenção e monitoramento das disparidades em saúde $(81,82)$.

Diferentes paradigmas e correntes de pensamento passaram a embasar as iniciativas científicas e as das agências, governamentais ou não, cujas atividades convergem para o campo das iniqüidades em saúde. Nesse campo, Gwatkin (79) identificou três corren-tes de pensamento, que poderiam ser designadas pelo seu enfoque central: pobreza e saúde, desigualdades em saúde e iniqüidades em saúde. $\mathrm{O}$ reconhecimento inconteste do grau extremo e superável das desigualdades sociais expressas nos níveis de saúde, as disparidades sociais crescentes entre países e entre classes sociais e frações em diferentes países e regiões, sob o impacto das políticas econômicas alinhadas aos moldes do processo de globalização e das políticas sociais contidas e restritas, e um processo crescente e inumano de exclusão social formaram o caldo em que germinam estudos científicos e iniciativas. A dimensão do problema levou à criação, em junho de 2000, da sociedade internacional para a eqüidade em saúde (International Society for Equity in Health), cuja conferência inaugural teve lugar em Havana.

No presente momento, em que o debate epistemológico sobre a epidemiologia aponta, de um lado, para a possibilidade de uma completa separação entre esta e seu objeto coletivo, e de outro, para a iminente modificação de seus limites e paradigma, o recrudescimento dos estudos sobre iniqüidades em saúde constrói um espaço de muitas possibilidades para que a epidemiologia venha a retomar seu papel de inteligência capaz de fornecer referenciais e instrumentos para a detecção e o monitoramento dessa face particular das injustiças sociais.
3. Cavalli A. Classe. Em: Bobbio N, Matteucci N, Pasquino G. Dicionário de política. Vol. I. $4^{\mathrm{a}}$ ed. Brasília: Editora Universidade de Brasília; 1992. Pp. 169-175. 
4. Cavalli A. Estratificação social. Em: Bobbio N, Matteucci N, Pasquino G. Dicionário de política. Vol. I. $4^{a}$ ed. Brasília: Editora Universidade de Brasília; 1992. Pp. 443-445.

5. Kadt E, Tasca R. Promovendo a eqüidade um novo enfoque com base no setor da saúde. São Paulo/Salvador: Hucitec/Cooperação Italiana em Saúde; 1993.

6. Boudon R, Bourricaud F. Dicionário crítico de sociologia. São Paulo: Ática; 1993.

7. Pastore J. Desigualdade e mobilidade social no Brasil. São Paulo: Editora da Universidade de São Paulo (Edusp); 1985.

8. Rousseau JJ. Discurso sobre a origem e os fundamentos da desigualdade entre os homens. 3rd ed. São Paulo: Abril Cultural, 1983. (Série Os Pensadores).

9. Marx K, Engels F. Manifesto do partido comunista. Em: Obras escolhidas. Tomo 1. Lisboa: Edições Progresso; 1982.

10. Przeworski A. Capitalismo e socialdemocracia. São Paulo: Companhia das Letras; 1989.

11. Elster J. Marx, hoje. Rio de Janeiro: Paz e Terra; 1989.

12. Weber M. Economía y sociedad. $2^{\mathrm{a}}$ ed. México: Fondo de Cultura Económica; 1987.

13. MacMahon B, Pugh TF. Epidemiology principles and methods. 1st ed. Boston: Little, Brown and Company; 1970.

14. Hipócrates. Aires, aguas y lugares. En: Buck, C, Llopis A, Najera E, Terris M, eds. El desafío de la epidemiología. Washington DC: Organización Panamericana de la Salud; 1988. Pp. 18-19. (Publicación Científica no 505).

15. Snow J. Sobre a maneira de transmissão do cólera. 2nd ed. São Paulo/Rio de Janeiro: Hucitec/Associação Brasileira de Pós-Graduação em Saúde Coletiva (Abrasco); 1990.

16. Mendes R, Dias EC. Saúde do trabalhador. Em: Rouquayrol MZ. Epidemiologia \& saúde. $4^{a}$ ed. Rio de Janeiro: MEDSI Editora Médica e Científica; 1994. Pp. 383-402.

17. Goldberg M. Este obscuro objeto da epidemiologia. Em: Costa DC, ed. Epidemiologia: teoria e objeto. São Paulo/Rio de Janeiro: Hucitec/Associação Brasileira de Pós-Graduação em Saúde Coletiva (Abrasco); 1990.

18. Schellekens J. Mortality and socio-economic status in two eighteenth-century Dutch villages. Popul Stud (Camb) 1989;43(3):391-404.

19. Terris M. Discusión. En: Buck C, Llopis A, Nájera E, Terris M, eds. El desafío de la epidemiología. Washington DC: Organización Panamericana de la Salud; 1988. Pp. 3-17. (Publicación Científica 505).

20. Dallemagne J, Nair S. A economia política, o socialismo utópico. Em: Châtelet $\mathrm{F}$, ed. História da filosofia. Vol. 5. $2^{\mathrm{a}}$ ed. Rio de Janeiro: Zahar; 1981. Pp. 124-169.

21. Rosen G. Uma história da saúde pública. São Paulo: Universidade Estadual Paulista (UNESP)/HUCITEC/Associação Brasileira de Pós-Graduação em Saúde Coletiva (Abrasco); 1994

22. Breilh J. Epidemiologia: economia, política e saúde. São Paulo: UNESP; 1991.

23. Jones GS. Retrato de Engels. Em: Hobsbawn EJ. História do marxismo. Vol. 1. $2^{\mathrm{a}} \mathrm{ed}$. Rio de Janeiro: Paz e Terra; 1983. Pp. 377-422.
24. Engels F. La situación de la clase obrera en Inglaterra. Ciudad de México: Cultura Popular; 1984.

25. Duchesneau F. A filosofia anglo-saxônica de Bentham a W. James. Em: Châtelet F, ed. História da filosofia. Vol. 6. $2^{\text {a }}$ ed. Rio de Janeiro: Zahar; 1983. Pp. 113-137.

26. Villermé LR. Reseña del estado físico y moral de los obreros de las industrias del algodón, la lana y la seda. En: Buck C, Llopis A, Nájera E, Terris M, eds. El desafío de la epidemiología. Washington DC: Organización Panamericana de la Salud; 1988. Pp. 34-37. (Publicación Científica 505).

27. Power C, Manor O, Fox J. Health and class: the early years. London: Chapman \& Hall; 1991

28. Farr W. Mortalidad de los mineros: una selección de los informes y escritos de William Farr. En: Buck C, Llopis A, Nájera E Terris M, eds. El desafío de la epidemiología. Washington DC: Organización Panamericana de la Salud; 1988. Pp. 69-73. (Publicación Científica 505)

29. Bernhardt J. Química e biologia no século XIX Em: Châtelet F, ed. História da filosofia. Vol. 6. $2^{\mathrm{a}}$ ed. Rio de Janeiro: Zahar; 1983. Pp. 61112

30. Omram AR. The epidemiologic transition: a theory of the epidemiology of population change. Milbank Mem Fund Q 1971;49(4) 509-538.

31. Goldberger J. Estudios sobre la pelagra. En: Buck C, Llopis A, Nájera E, Terris M, eds. El desafío de la epidemiología. Washington DC: Organización Panamericana de la Salud; 1988 Pp. 101-105. (Publicación Científica 505).

32. Jones IG, Cameron D. Social class analysis an embarrassment to epidemiology. Community Med 1984;6(1):37-46.

33. Greenwood M. Epidemiología del cáncer. En: Buck C, Llopis A, Nájera E, Terris M, eds. E desafío de la epidemiología. Washington DC: Organización Panamericana de la Salud; 1988 Pp. 115-125. (Publicación Científica 505).

34. Illsley R, Baker D. Contextual variations in the meaning of health inequality. Soc Sci Med 1991;32(4):359-365.

35. Antonovsky A. Social class, life expectancy and overall mortality. Milbank Mem Fund Q 1967;45(2):31-73

36. Lilienfeld AM, Lilienfeld DE. Foundations of epidemiology. 2nd ed. New York/Oxford: Oxford University Press; 1980

37. Liberatos P, Link BG, Kelsey JL. The measurement of social class in epidemiology. Epidemiol Rev 1988;10:87-121.

38. Nunes ED. Trayectoria de la medicina social en América Latina: elementos para su configuración. En: Franco SA, Nunes E, Breihl J, Laurell C. Debates en medicina social. Quito: Organización Panamericana de la Salud; 1991. Pp. 17-137.

39. Breilh J, Granda E. Investigación de la salud en la sociedad. Quito: Centro de Estudios y Asesoría en Salud (CEAS); 1980.

40. Barros MBA. Saúde e classe social: um estudo sobre morbidade e consumo de medicamentos, Ribeirão Preto [tese]. Ribeirão Preto: Universidade de São Paulo; 1983.

41. Townsend P, Davidson N, eds. Inequalities in health: the Black report. Harmondsworth: Penguin Books; 1992.
42. Svensson P. Health inequities in Europe: introduction. Soc Sci Med 1990;31(3):225-227.

43. Taubes G. Epidemiology faces its limits. Science 1995;269(5521):164-169.

44. Larkin M. Epidemiological studies: overdone or underappreciated? Lancet 2000;355(9203): 556

45. Holland WW. The hazards of epidemiology [editorial]. Am J Public Health 1995;85(5):616617.

46. Susser M, Susser E. Choosing a future for epidemiology: II. From black box to Chinese boxes and eco-epidemiology. Am J Public Health 1996;86(5):674-677.

47. Krieger N. Epidemiology and the web of causation: has anyone seen the spider? Soc Sci Med 1994;39(7):887-903.

48. Shy C. The failure of academic epidemiology: witness for the prosecution. Am J Epidemio 1997;145(6):479-484.

49. Pearce N. Traditional epidemiology, modern epidemiology and public health. Am J Public Health 1996;86(5):678-683.

50. Kaufman JS, Cooper RS. Seeking causal explanation in social epidemiology. Am J Epidemiol 1999;150(2):113-120.

51. Rothman KJ, Adami HO, Trichopoulos D. Should the mission of epidemiology include the eradication of poverty? Lancet 1998; 352(9130):810-813.

52. Gori GB. Epidemiology and public health: is a new paradigm needed or a new ethic? J Clin Epidemiol 1998;51(8):637-641.

53. Wall S. Epidemiology in transition. Int J Epidemiol 1999;28(5):1000-1004.

54. Holland W. What should be the concerns of epidemiology? Int J Epidemiol 1999;28(5): 1009-1011.

55. Pearce N. Epidemiology as a population science. Int J Epidemiol 1999;28(5):1015-1018.

56. Zielhuis GA, Kiemeney LA. Social epidemiology? No way. Int J Epidemiol 2001;30(1):43- 44.

57. Barreto M. Por uma epidemiologia da saúde coletiva. Rev Bras Epidemiol 1998;1(2):104130 .

58. Kunst AE. Cross-national comparisons of socio-economic differences in mortality [thesis]. Rotterdam, Netherlands: Erasmus University; 1997.

59. Borrell C. Métodos utilizados no estudo das desigualdades sociais em saúde. Em: Barata RB, ed. Condições de vida e situação de saúde. Rio de Janeiro: Associação Brasileira de Pós-Graduação em Saúde Coletiva (Abrasco); 1997. Pp. 167-195.

60. Mackenbach JP, Kunst AE, Cavelaars EJM Groenhof F, Geurts JJM. Socioeconomic inequalities in morbidity and mortality in western Europe. The EU Working Group on Socioeconomic Inequalities in Health. Lancet 1997;349(9066):1655-59.

61. Martikainen P, Ishizaki M, Marmot MG, Nakagawa, H, Kagamimori S. Socioeconomic differences in behavioural and biologic risk factors: a comparison of a Japanese and an English cohort of employed men. Int J Epidemiol 2001;30(4):833-838.

62. Singh GK, Yu SM. US Childhood mortality, 1950 through 1993: trends and socioeconomic differentials. Am J Public Health 1996;86(4): $505-512$ 
63. Singh GK, Yu SM. Trends and differentials in adolescent and young adult mortality in the United States, 1950 through 1993. Am J Public Health 1996;86(4):560-564.

64. International Agency for Research on Cancer (IARC). Social Inequalities and Cancer. Lyon: IARC; 1997. (IARC Scientific Publications, 138).

65. Bennet S. Socioeconomic inequalities in coronary heart disease and stroke mortality among Australian men, 1979-1993. Int J Epidemiol 1996;25(2):266-275.

66. Heck KE, Wagener DK, Schatzkin A, Devesa SS, Breen N. Socioeconomic status and breast cancer mortality, 1989 through 1993: an analysis of education data from death certificates. Am J Public Health 1997;87(7):1218-1222.

67. Westerling R, Gullberg A, Rosén M. Socioeconomic differences in "avoidable" mortality in Sweden, 1986-1990. Int J Epidemiol 1996; 25(3):560-567.

68. Martikainen P, Valkonen T. Bias related to the absence of information on occupation in studies on social class differences in mortality. Int J Epidemiol 1999;28(5):899-904.

69. Jarvis MJ, Wardle J. Social patterning of individual health behaviours: the case of cigarette smoking. In: Marmot M, Wilkinson RG. Social determinants of health. New York: Oxford University Press; 1999. Pp. 240-255.

70. Power C, Matthews S, Manor O. Inequalities in self-rated health: explanations from different stages of life. Lancet 1998;351(9108):1009- 1114

71. National Institutes of Health. Recommendations of the conference
"Measuring Social Inequalities in Health". Int J Health Serv 1996; 26(3):521-527.

72. Gakidou EE, Murray CJL, Frenk J. Defining and measuring health inequalities: an approach based on the distribution of health expectancy. Bull World Health Organ 2000; 78(1):42-54.

73. Wilkinson RG. Income distribution and life expectancy. Br Med J 1992;304(6820):165-168.

74. Kaplan GA, Pamuk ER, Lynch JW, Cohen RD, Balfour JL. Inequality in income and mortality in the United States: analysis of mortality and potential pathways. Br Med J 1996;312(7037): 999-1003.

75. Lynch JW, Kaplan GA, Pamuk ER, Cohen RD, Heck KE, Balfour JL, et al. Income inequality and mortality in metropolitan areas of the United States. Am J Public Health 1998;88(7): 1074-1080.

76. Szwarcwald CL, Bastos FI, Esteves MAP, Andrade CLT, Paez MS, Medici EV, et al. Desigualdade de renda e situação de saúde: o caso do Rio de Janeiro. Cad Saude Publica 1999;15(1):15-28.

77. World Health Organization (WHO). Equity in health and in health care: a World Health Organization initiative. Geneva: WHO; 1996.

78. Pan American Health Organization (PAHO). The search for equity: annual report of the Director, 1995. Washington, DC: PAHO; 1995.

79. Gwatkin DR. Health inequalities and the health of the poor: What do we know? What can we do? Bull World Health Organ 2000; 78(1):3-18.

80. Barata RB, Barreto ML, Almeida Filho N, Veras RP, eds. Eqüidade e saúde: contribuições da epidemiologia. Rio de Janeiro:
Fundação Instituto Oswaldo Cruz/Associação Brasileira de PósGraduação em Saúde Coletiva (Abrasco); 1997.

81. Nunes A, Santos JRS, Barata RB, Vianna SM Medindo as desigualdades em saúde no Brasil: uma proposta de monitoramento. Brasília: Organização Pan-Americana da Saúde/Instituto de Pesquisa Econômica Aplicada; 2001.

82. Duarte EC, Schneider MC, Paes-Sousa R, Ramalho WM, Vasconcelos Sardinha LM, Silva Júnior JB, et al. Epidemiologia das desigualdades em saúde no Brasil: um estudo exploratório. Brasília: Organização PanAmericana da Saúde; 2002

Manuscrito recebido em 8 de fevereiro de 2002. Aceito em versão revisada em 13 de junho de 2002

ABSTRACT In this paper we present a historical analysis of the concept of inequality, and we also discuss how inequality has been viewed within the field of health. Natural and social inequalities are discussed, along with the concept of equity, theoretical explanations

\section{Epidemiology and inequality: notes on theory and history} for inequality, and stratification in modern societies. Finally, we focus on the relationships between epidemiology and studies on social inequalities in health since epidemiology was established as a discipline, during the so-called bacteriological era, and at the present time, when there is a growing interest in social inequalities in health. 